\title{
Association of Oesophageal Varices and Splanchnic Vein Thromboses in Patients with JAK2-Positive Myeloproliferative Neoplasms: Presentation of Two Cases and Data from a Retrospective Analysis
}

\author{
Cornelia S. Link ${ }^{a} \quad$ Uwe Platzbecker $^{\mathrm{a}} \quad$ Frank Kroschinsky $^{\mathrm{a}} \quad$ Sven Pannach $^{\mathrm{a}}$ \\ Christian Thiede $^{\mathrm{a}} \quad$ Ivan Platzek $^{\mathrm{b}} \quad$ Gerhard Ehninger $^{\mathrm{a}} \quad$ Markus K. Schuler $^{\mathrm{a}}$ \\ Departments of ${ }^{\mathrm{a}}$ Medicine I and ${ }^{\mathrm{b}}$ Radiology, Dresden Technical University, \\ Dresden, Germany
}

\section{Key Words}

Oesophageal varices · Variceal bleeding · Splanchnic vein thrombosis · Portal vein thrombosis $\cdot$ JAK2 $\cdot$ Myeloproliferative neoplasms

\begin{abstract}
Background: Oesophageal varices and gastrointestinal bleeding are common complications of liver cirrhosis. More rarely, oesophageal varices occur in patients with non-cirrhotic portal hypertension that results from thromboses of portal or splanchnic veins. Case Report: We describe 2 young men who initially presented with varices as a result of portal vein thromboses. In the clinical follow-up, both were tested positive for a JAK2 mutation and consequently diagnosed with myeloproliferative neoplasms (MPNs). In an attempt to characterise the frequency of gastrointestinal complications in patients with JAK2-positive MPNs, we retrospectively analysed all known affected patients from our clinic for the diagnosis of portal vein thromboses and oesophageal varices. Strikingly, $48 \%$ of those who had received an oesophagogastroduodenoscopy had detectable oesophageal or gastric varices, and $82 \%$ of those suffered from portal or splanchnic vein thromboses. Conclusion: While the association between JAK2, myeloproliferative disease and thrombotic events is well established, patients with idiopathic oesophageal varices are not regularly tested for JAK2 mutations. However, the occurrence of oesophageal varices may be the first presenting symptom of a MPN with a
\end{abstract}


JAK2 mutation, and affected patients may profit from a close haematological monitoring to assure the early detection of developing MPN.

\section{Introduction}

Oesophageal varices and gastrointestinal bleeding are common complications of patients with liver cirrhosis. However, more rarely, varices of oesophageal and gastric veins also occur in patients with non-cirrhotic portal hypertension that may result from splanchnic vein thrombosis, including the portal and splenic veins. Myeloproliferative neoplasms (MPNs) are one of the risk factors for the development of splanchnic vein thrombosis [1, 2].

MPNs are a heterogeneous group of haematological disorders that are divided into 2 large subgroups depending on the presence of the Bcr-Abl fusion protein. Bcr-Abl-negative MPNs include myelofibrosis (MF), essential thrombocythaemia (ET) and polycythaemia vera (PV). While these conditions are not defined by a single molecular mutation, they share a number of similarities. Common features are activating mutations of Janus kinase 2 (JAK2), which is a key player in the regulation of haematopoiesis. JAK2 mutations can be found in approximately $48 \%$ of ET and MF cases and in almost all PV cases [3, 4].

Testing for JAK2 mutations has become an important tool to identify Bcr-Abl-negative MPNs, including those that may be 'occult' in patients presenting with splanchnic vein thrombosis $[4,5]$. JAK2 mutational analysis to detect Bcr-Abl-negative MPNs can precede the clinical onset and diagnostic criteria as defined by the WHO in $2008[6,7]$. While the association between JAK2, MPN and thrombotic events is well established, patients with idiopathic oesophageal varices are not regularly tested for the presence of JAK2 mutations.

\section{Case Series}

Here, we describe 2 young men with JAK2 mutation-associated portal hypertension and bleeding complications due to oesophageal varices. The first patient, a 35-year-old man, was referred to our tertiary hospital for the evaluation of portal and splenic vein thromboses associated with severe abdominal pain and a slight thrombocytosis $\left(500 \times 10^{9}\right.$ platelets/l). Angiography revealed a cavernous transformation of the portal vein associated with multiple collateral veins, splenomegaly and portal hypertension (fig. 1). Oesophagogastroduodenoscopy (OGD) showed varices of the oesophageal and gastric veins that required ligation (fig. 2). Following this immediate therapy, the patient was anticoagulated with twice-daily injections of low-molecular-weight heparin. Bone marrow analysis was compatible with the diagnosis of ET. As approximately $50 \%$ of patients with ET suffer from a JAK2 mutation [4], appropriate genetic testing was performed, which confirmed a JAK2 mutation. In the first 6 months after diagnosis, an OGD with required ligation of the oesophageal varices had to be performed 5 times. One and a half years later, stable disease (OGD once a year) was achieved with concomitant therapy of propranolol (80 mg twice a day).

Another 35-year-old man with abdominal pain and recurrent chills for 4 months presented at our clinic with splenomegaly and cavernous transformation of the portal vein (fig. 3). Although this patient did not have haematological abnormalities, screening for JAK2 mutation turned out positive. The patient also had third-degree oesophageal varices with signs of immediate bleeding. Initially the patient refused to undergo ligation. In further haematological follow-up, the patient was diagnosed with prefibrotic MF, as proven by bone 
Link et al.: Association of Oesophageal Varices and Splanchnic Vein Thromboses in Patients with JAK2-Positive Myeloproliferative Neoplasms: Presentation of Two Cases and Data from a Retrospective Analysis

marrow biopsy. This patient repeatedly underwent OGDs and ligation of the oesophageal varices. Upon beginning of ruxolitinib (a JAK2 inhibitor) and low-dose propranolol (6.25 $\mathrm{mg}$ twice a day), the frequency of required ligation was considerably reduced. Both patients now receive close haematological and gastroenterological monitoring.

\section{Discussion}

Our data highlight the clinical relevance of oesophageal varices in MPN patients with JAK2 mutations. Data from another study investigating MPN and portal vein thrombosis showed that in $18 \%$ of cases the presenting symptom of a MPN was variceal bleeding. Furthermore, $39 \%$ of those patients had at least 1 episode of gastrointestinal bleeding in the course of their disease [8]. In most patients (70\%), the detection of portal vein thromboses was the initial manifestation of a MPN [8].

In our retrospective analysis of 123 JAK2-positive patients, a total of 23 patients had received an OGD. Eleven (48\%) were diagnosed with oesophageal varices. Nine $(82 \%)$ of these patients also showed thromboses of the portal $(7 / 11)$, mesenteric $(3 / 11)$, liver $(1 / 11)$ and/or splenic $(5 / 11)$ veins. Two patients were JAK2 positive and had varices without splanchnic vein thromboses. In one of them, the varices were caused by liver cirrhosis, and in the other case, cardiac insufficiency lead to portal hypertension. Vice versa, in all JAK2positive patients without varices, no cases of splanchnic vein thrombosis were detected.

Until now, there has been no data to indicate any prognostic differences between MPN patients with and without oesophageal varices, since an OGD is not a standard procedure in this group [7]. While emerging chemotherapeutic options for palliation of constitutive symptoms are available and specific JAK inhibitors improve disease-related problems and overall survival in patients with MPN [9], the monitoring of varices in the course of the disease has become an increasingly relevant issue. As previously reported, ruxolitinib is a therapeutic option for patients with MF to reduce splenomegaly and associated symptoms $[10,11]$. However, the monitoring of oesophageal varices has not been implemented into disease guidelines yet $[7,9]$.

The association between JAK2 mutation, oesophageal varices and portal vein thrombosis should translate into direct clinical consequences for the affected patients. The primary aim is to avoid life-threatening variceal bleeding and the early detection of MPNs. In a series reported by Condat et al. [12], gastrointestinal bleeding occurred with an incidence of $12.5 / 100$ patient-years in an unselected cohort of patients with portal vein thrombosis. The high incidence of gastrointestinal bleeding in patients with portal vein thrombosis and the association between oesophageal varices and JAK2-related splanchnic vein thromboses should be kept in mind when seeing such patients.

\section{Conclusion}

In summary, our report suggests that an OGD should be recommended in patients with MPN and confirmed JAK2 mutations to detect asymptomatic varices of the oesophageal or gastric veins. This helps to adequately assess the risk of further complications and to initiate therapeutic measures when needed. On the other hand, testing for JAK2 mutations could be a valuable tool for the early identification of an occult MPN in patients presenting with oesophageal or gastric varices. 


\section{Case Reports in Oncology}

\section{Disclosure Statement}

The authors declare no conflicts of interest.
(C) 2013 S. Karger AG, Basel www.karger.com/cro

Link et al: Association of Oesophageal Varices and Splanchnic Vein Thromboses in Patients with JAK2-Positive Myeloproliferative Neoplasms: Presentation of Two Cases and Data from a Retrospective Analysis

\section{References}

$\checkmark 1$ Colaizzo D, Amitrano L, Tiscia GL, Scenna G, Grandone E, Guardascione MA, Brancaccio V, Margaglione M: The JAK2 V617F mutation frequently occurs in patients with portal and mesenteric venous thrombosis. J Thromb Haemost 2007;5:55-61.

-2 Orr DW, Patel RK, Lea NC, Westbrook RH, O’Grady JG, Heaton ND, Pagliuca A, Mufti GJ, Heneghan MA: The prevalence of the activating JAK2 tyrosine kinase mutation in chronic porto-splenomesenteric venous thrombosis. Aliment Pharmacol Ther 2010;31:1330-1336.

-3 Baxter EJ, Scott LM, Campbell PJ, East C, Fourouclas N, Swanton S, Vassiliou GS, Bench AJ, Boyd EM, Curtin N Scott MA, Erber WN, Green AR: Acquired mutation of the tyrosine kinase JAK2 in human myeloproliferative disorders. Lancet 2005;365:1054-1061.

-4 Smalberg JH, Koehler E, Darwish Murad S, Plessier A, Seijo S, Trebicka J, Primignani M, de Maat MP, GarciaPagan JC, Valla DC, Janssen HL, Leebeek FW: The JAK2 46/1 haplotype in Budd-Chiari syndrome and portal vein thrombosis. Blood 2011;117:3968-3973.

5 Dentali F, Squizzato A, Brivio L, Appio L, Campiotti L, Crowther M, Grandi AM, Ageno W: JAK2V617F mutation for the early diagnosis of $\mathrm{Ph}$ - myeloproliferative neoplasms in patients with venous thromboembolism: a meta-analysis. Blood 2009;113:5617-5623.

6 Swerdlow SH, Campo E, Harris NL, Jaffe ES, Pileri SA, Stein H, Thiele J, Vardiman JW: WHO Classification of Tumours of Haematopoietic and Lymphoid Tissues. Geneva, WHO Press, 2008.

7 Tefferi A: Primary myelofibrosis: 2012 update on diagnosis, risk stratification, and management. Am J Hematol 2011;86:1017-1026.

$>8$ Hoekstra J, Bresser EL, Smalberg JH, Spaander MC, Leebeek FW, Janssen HL: Long-term follow-up of patients with portal vein thrombosis and myeloproliferative neoplasms. J Thromb Haemost 2011;9:2208-2214.

-9 Barbui T: How to manage thrombosis in myeloproliferative neoplasms. Curr Opin 0ncol 2011;23:654-658.

10 Ganetsky A: Ruxolitinib: a new treatment option for myelofibrosis. Pharmacotherapy 2013;33:84-92.

-11 Harrison C, Kiladjian JJ, Al-Ali HK, Gisslinger H, Waltzman R, Stalbovskaya V, McQuitty M, Hunter DS, Levy R, Knoops L, Cervantes F, Vannucchi AM, Barbui T, Barosi G: JAK inhibition with ruxolitinib versus best available therapy for myelofibrosis. N Engl J Med 2012;366:787-798.

12 Condat B, Pessione F, Hillaire S, Denninger MH, Guillin MC, Poliquin M, Hadengue A, Erlinger S, Valla D: Current outcome of portal vein thrombosis in adults: risk and benefit of anticoagulant therapy. Gastroenterology 2001;120:490-497.

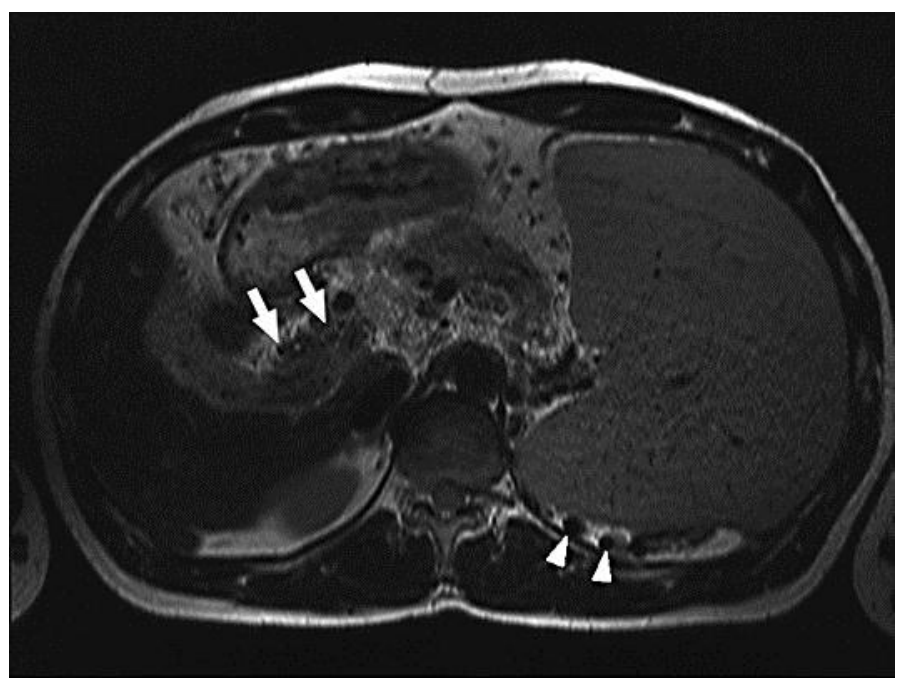

Fig. 1. T2-weighted turbo spin-echo image in axial orientation showing splenomegaly, cavernous transformation of the portal vein (white arrows) and varices (white arrowheads). 


\section{Case Reports in Oncology}

\begin{tabular}{l|l}
\hline Case Rep Oncol 2013;6:311-315 \\
\hline DOI: 10.1159/000352088 & $\begin{array}{l}\text { (c) 2013 S. Karger AG, Basel } \\
\text { www.karger.com/cro }\end{array}$ \\
\hline
\end{tabular}

Link et al.: Association of Oesophageal Varices and Splanchnic Vein Thromboses in Patients with JAK2-Positive Myeloproliferative Neoplasms: Presentation of Two Cases and Data from a Retrospective Analysis

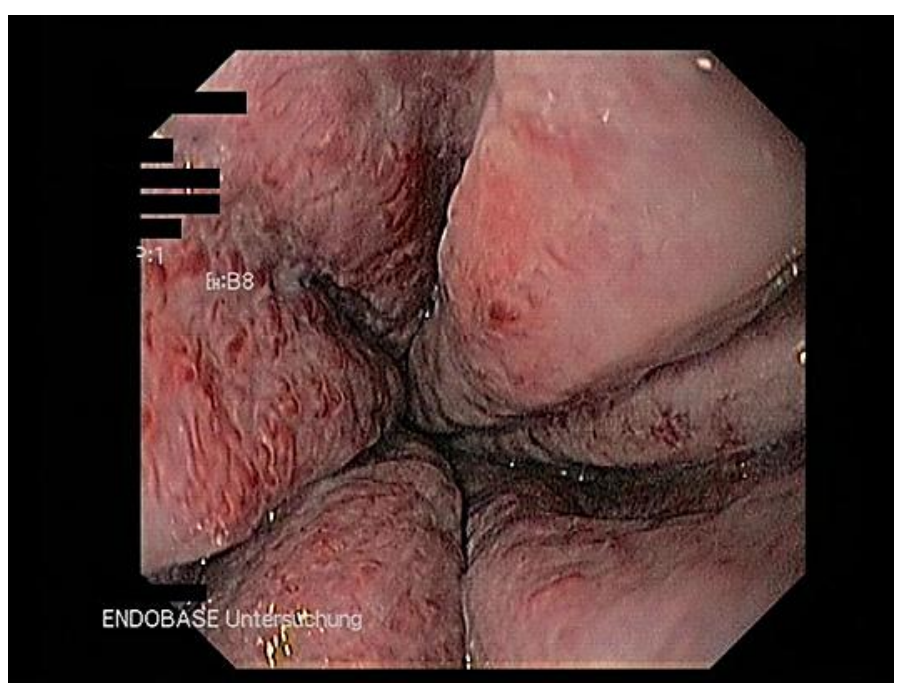

Fig. 2. Third-degree oesophageal varices with red spots. Varices exceed $50 \%$ of the intestinal lumen.

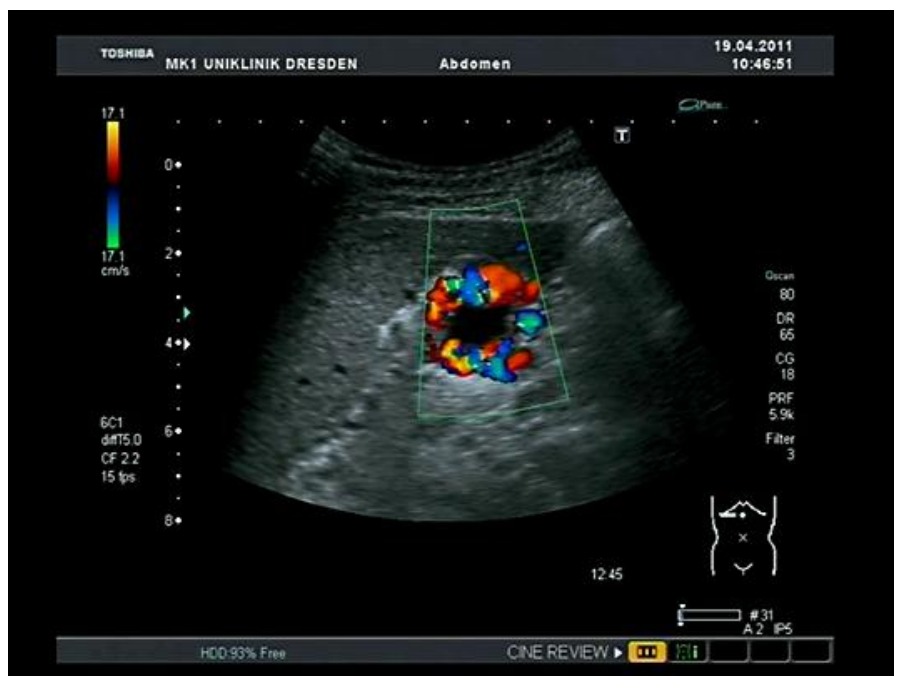

Fig. 3. Cavernous transformation of the portal vein on abdominal ultrasound. 